\title{
Income Patterns of Woman Workers in Pakistan - A Case Study of the Urban Manufacturing Sector
}

\author{
Asad Sayeed, Farhan Sami Khan and Sohail Javed ${ }^{*}$
}

\begin{abstract}
The paper analyses the income patterns of women workers employed in the urban manufacturing sector of Pakistan. It examines the wage differentials across regions, manufacturing sectors and industrial categories including large scale factories, small-scale enterprises and home based work. The central conclusion is that wages of women workers across sectors and industry size vary because of differences in the capital-labour ratio and hence labour productivity. The paper determines the proportion of women earning above and below the legally mandated minimum wage, which differs significantly across formal and informal industries. Finally, the earnings of workers have been examined in the context of human capital accumulation.
\end{abstract}

\section{Introduction}

In developing countries, participation of women in the labour force is increasing over time. ${ }^{1}$ This increased participation is mainly attributed to both push as well as pull factors. The push of increasing urbanisation, greater demand for consumer goods and the reduction in the 'social wage' ${ }^{2}$ has compelled a greater number of women to join the labour force. Similarly, increasing literacy and educational attainment amongst women and the desire for financial independence has created the requisite pull towards remunerative work.

While women are increasingly participating in the labour force, what are the economic returns or remuneration for which this participation in the labour market takes place? This is the central question that this paper

\footnotetext{
* Asad Sayeed and Sohail Javed are Director and Research Officer at the Collective for Social Science Research, Karachi respectively and Farhan Sami Khan is Research Officer at the Social Policy and Development Centre, Karachi. The authors wish to acknowledge logistical and financial support from the Pakistan Institute of Labour Education and Research (PILER) and the Canadian International Development Agency (CIDA) respectively.

${ }^{1}$ See Mammen and Paxson (2000) for a detailed cross-country study on increasing trends of female labour force participation in developing countries.

${ }^{2}$ Social wage refers to state provision and subsidisation of physical and social infrastructure as well as subsidies on important food items.
} 
seeks to understand in the context of Pakistan's urban manufacturing sector. Issues of returns to women's labour are central to understanding the terms on which women participate in the labour force.

Based on a survey of 630 woman workers, the results on returns to labour across a variety of categories are presented in section 2 . We have looked at wage differentials across industries, across different regions in Pakistan and across different levels of industrial organisation, i.e. formal large-scale industry, small-scale enterprises and home-based work. In section 3, we also check the extent to which human capital attainments in the form of schooling and experience impact on the returns to labour using the Mincerian wage equation. ${ }^{3}$ Before presenting the findings of the study, Section 1 provides a brief overview of the sampling distribution and methodology of the survey from which data is used.

\section{Sampling Distribution and Methodology of the Survey}

The actual sample size of the survey consisted of 616 blue-collar women workers in the urban manufacturing sector, however, in total 630 respondents were interviewed ${ }^{4}$. Because of the paucity of national, regional, and industry level data pertaining to employment of women workers in Pakistan, no sampling frame was available. Therefore the method of 'categorical sampling' has been adopted. Under the methodology, the sample has been divided by province, sector and type of industry. Across provinces, the sample has been distributed according to the manufacturing base of the province, based on the distribution provided in the Census of Manufacturing Industry (CMI) (1995-96), the latest complete survey available at the time of sampling. Each province is represented by its capital city, i.e. Karachi, Lahore, Peshawar and Quetta.' The rationale for selecting these cities was to capture the cultural differences which were important in analysing different gender roles across the country. ${ }^{6}$ In addition, these cities are also important hubs of manufacturing activities in each region, both in the formal and informal sectors. The distribution of the sample according to region is presented in chart 1 .

\footnotetext{
${ }^{3}$ The equation suggests that higher levels of earnings are associated with higher level of investments in human capital accumulation. Human capital investments could be made in a variety of ways such as through schooling, experience and training etc.

${ }^{4}$ The reason for doing so was to improve the precision of the sample for better results.

${ }^{5}$ The initial objective of the study was to conduct the survey in the major industrial cities of the provinces. However, time and financial constraints restricted us to conduct the survey in four cities only.

${ }^{6}$ An important dimension of the major study was to analyse the socio-cultural differences with respect to gender. For details, see Sayeed and Khattak (2001).
} 


\section{Chart 1: Percentage Distribution of Sample by}

City

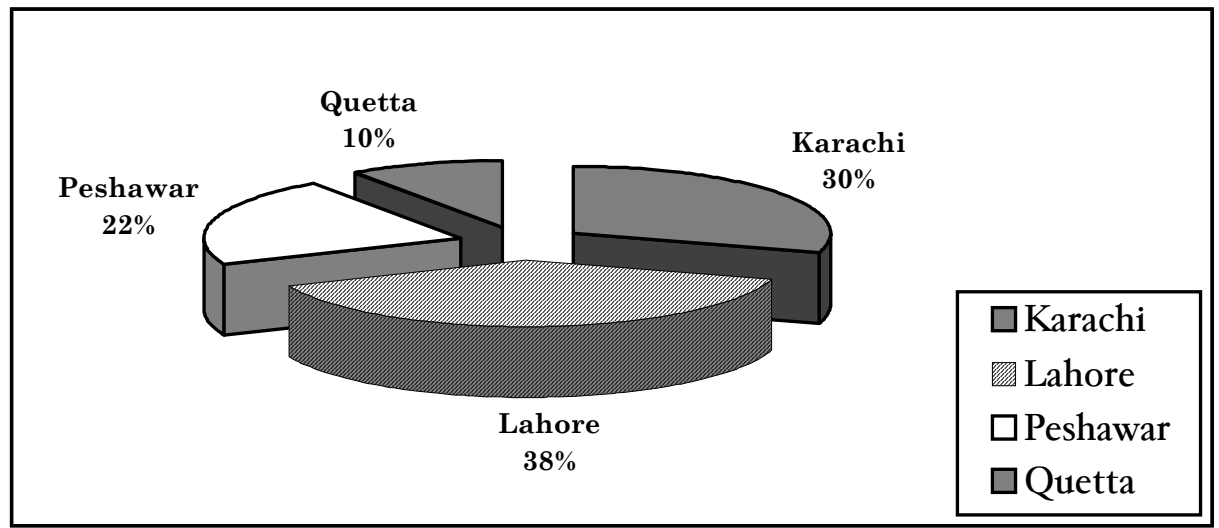

Similarly, the selection of industrial sectors namely garments, pharmaceuticals, plastic and food was based on relatively high levels of women's employment in these sectors as well as the probability of future growth of these industries and consequently of them being important hubs of women's employment in the foreseeable future. The distribution of the sample according to industrial sectors is presented in chart 2. This distribution is based on the relative employment share of the sectors based on data provided in the CMI and the Census of Small and Household Manufacturing Industries (CSHMI).

\section{Chart 2: Percentage Distribution of Sample by Sector}

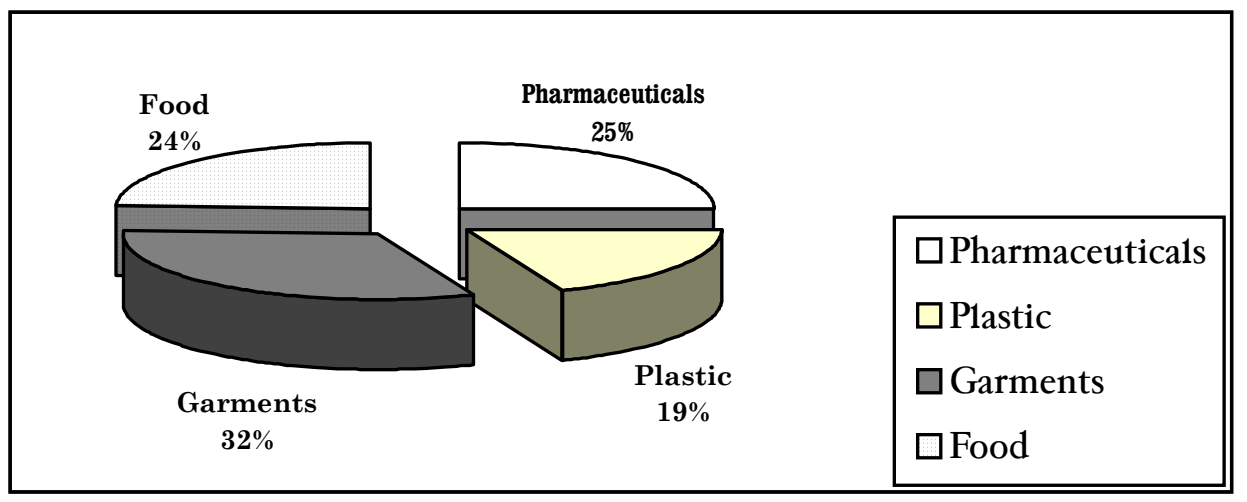

Within each industrial sector, the respondents were interviewed from both the formal and informal sectors (including small-scale units and home based work). The inclusion of the informal sector is of particular importance as over the years, incremental employment of women has 
primarily taken place in the informal sector (Kazi and Sathar, 1993 and Kazi, 1999). The sample distribution by industry type is given in chart 3 . Distribution between the formal and informal sectors is based on data provided by the Labour Force Survey 1996-97 pertaining to women's employment in these two categories. Since the Labour Force Survey does not provide any information about distribution of work within the informal sector, i.e. between small scale establishments and home-based work, based on an increasing trend of home-based work (see Kazi, 1999), slightly more weight has been given to home based work.

Chart 3: Percentage Distribution of Sample by Industry Type

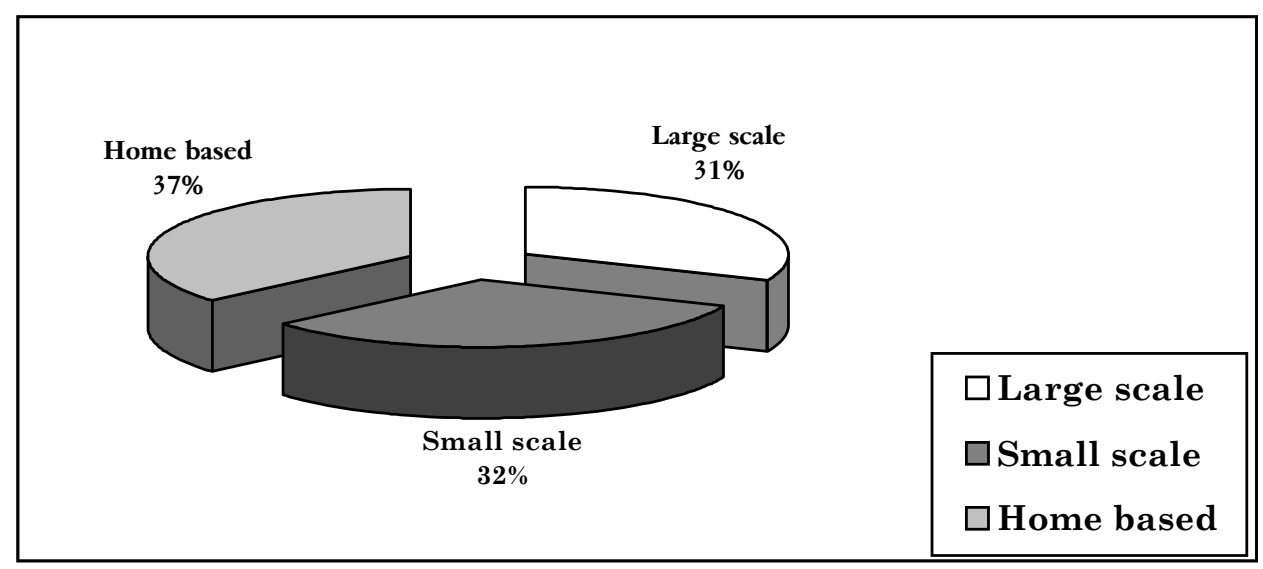

\section{Income Patterns of Women Workers}

How much do women earn from remunerative work and what is the pattern across regions, sectors and industry type? This section will discern these issues on the basis of our survey results. The information gathered through the survey will also enable us to test some hypotheses that have important policy implications. Where do average wages for women workers stand vis a vis the minimum wage in the country? Are wages higher in the formal sector compared to the informal sector and what are the differentials across different informal arrangements (small industry and home-based work)? To what extent do industries exhibit different wage patterns given different productivity and demand profiles in our sample? And finally do labour markets for women workers operate differently across the different regions surveyed? 


\subsection{Income Level}

In the sample as a whole, the median monthly income of women workers $^{7}$ comes to Rs. 1950 per month or roughly US \$ 33.6. The ideal comparator for wages would have been time-series data on wages in the same industries and sectors. Unfortunately neither is there any information on wages in these sectors, nor is there any wage data on manufacturing workers as a whole, and for woman workers in particular. ${ }^{8}$ In the absence of such information, one notional benchmark to gauge the level of income is to compare it with the official minimum wage in Pakistan. ${ }^{9}$ Because this is the legally mandated floor wage for workers, it serves as a useful benchmark in the absence of a more direct comparison of past wages. At the time of the survey (in late 1999 and early 2000) the official minimum wage in Karachi was Rs. 2050 per month whereas in other cities it was Rs. 1950 per month. For the sake of convenience we will use the simple average of the two, i.e. Rs.2000/month as the cut-off point for our income analysis.

In Table 1, we see that in the aggregate sample, more than two thirds of women workers work below the official minimum wage. The comparison of incomes with respect to the minimum wage in Table 1 is based on the nominal minimum wage as instituted in 1992. If we adjust it with the Sensitive Price Index (SPI) for the year 2000 (when much of the survey took place) it would come to Rs. 4,550 per month. On this benchmark, a substantial proportion i.e. 94 per cent of the sampled women is working below the minimum wage.

\section{Table 1. Incomes: Below and Above the Minimum Wage (in Rs. per month)}

\begin{tabular}{lll}
\hline Income Level & No. of Workers & \% of the Sample \\
\hline Below Rs. 2000 & 396 & 62.8 \\
Above Rs. 2000 & 234 & 37.1 \\
Total & 630 & 99.9 \\
\hline
\end{tabular}

\footnotetext{
${ }^{7}$ We have presented the median income levels rather than the mean because the standard deviation of income in the sample was very high. This is true both for the aggregate as well as across regions, industry types and sectors.

8 The CMI and CSHMI provide data on total labour cost and the number of workers. However it does not differentiate this information according to gender.

${ }^{9}$ Although minimum wage fixation in Pakistan does not take place on objective criteria (for further details, see Sayeed 2002), it is nevertheless a benchmark from which the fairness or otherwise of returns to labour can be ascertained.
} 


\subsection{Income Differentials in the Formal and Informal Sectors}

A priori one would expect that incomes from work in the registered large scale manufacturing industry (LSM) would be higher than in the informal sector (both small manufacturing units and home based work). The higher-capital labour ratio in the LSM sector as well as greater applicability of labour laws in this sector are factors that give rise to the hypothesis that wages will be higher in LSM compared to the informal sector. ${ }^{10}$ Within the informal sector, incomes in small industry are expected to be higher than in home-based work. Small industry would generally have a regular pattern of work, the capital labour ratio (and hence labour productivity) is expected to be higher and because of proximity of workers to each other they should be able to negotiate (explicitly or implicitly) for better wages.

In the aggregate, our data confirms this hypothesis. As we see in Table 2, the median income is higher among those working in the formal sector compared to the informal sector. However, this result is not as strong as hypothesised.

Table 2. Incomes in Formal and Informal Sectors (in Rs. per Month)

\begin{tabular}{ll}
\hline Industry & Income \\
\hline Formal & 2100 \\
Informal & 1600 \\
\hline
\end{tabular}

The differential in the median wage between the formal and informal sectors comes to roughly one fourth, i.e. the wages in the informal sector are one fourth less than those in the formal sector. Considering that the difference in the capital-labour ratio and in labour productivity between the two sectors is much more than one-fourth, the wage differential appears low. We hypothesise instead that this wage differential has more to do with the low level of wages paid in the formal sector due to the unregulated nature of employment in this sector.

By further disaggregating data, we can compare the proportion of women workers working below the official minimum wage in the formal and informal sectors. In Chart 4, we see that roughly seventy per cent of

\footnotetext{
${ }^{10}$ The formality of the industry however does not necessarily correspond to the formality of the employment contract. Indeed an increasing number of workers in the formal sector are informally employed though contractors and do not have access to legal provisions of a minimum wage, regulated working hours, leave provisions, pensions, gratuity, etc.
} 
working women in the informal sector work below the minimum wage. This is not a surprising result for reasons mentioned above. The important result is that roughly half the women who were interviewed in the formal sector work at less than the official minimum wage. This phenomenon is borne out of the informality of the employment contract in the formal sector. ${ }^{11}$ Since our results do not represent the actual universe of women workers employed in Pakistan's urban manufacturing sector, this phenomenon requires further examination at the national level.

Chart 4: Sectoral Incomes Above and Below Minimum Wage

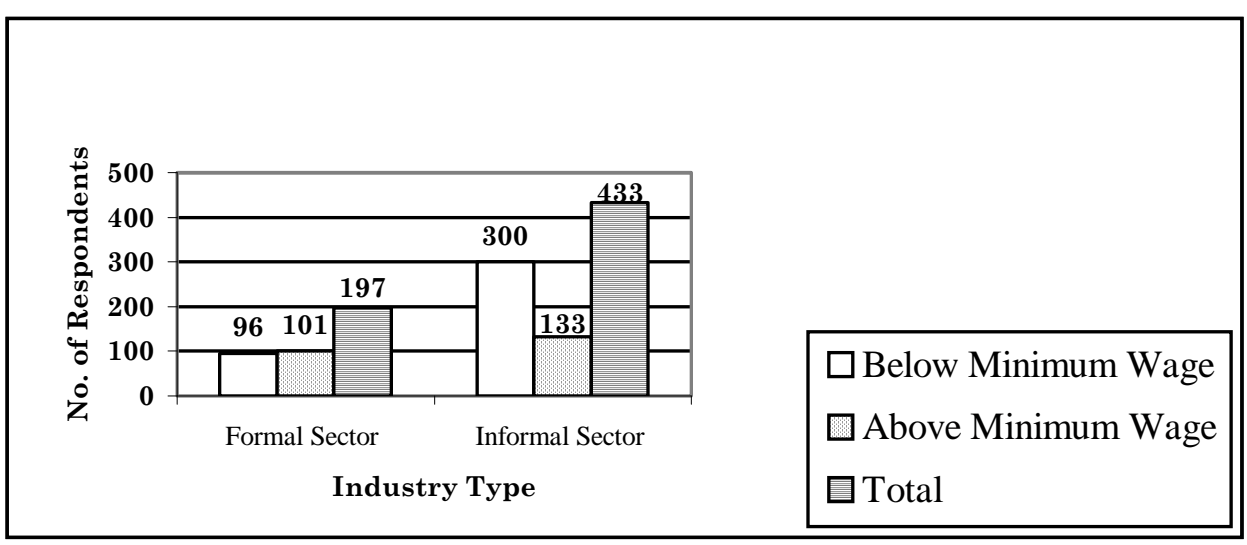

Within the informal sector the median wage differential between small scale industry and home based work is again roughly one fourth (Table 3). At this level of aggregation, the hypothesis stated above appears to hold. It also corroborates findings in an earlier study, which showed that incomes in home-based work were lower than those of small factory workers (Kazi and Sathar, 1993). Based on our field observations, two important differences between small factory and home-based work appear to explain this wage differential. Firstly, women in small factories were more aware of what others were being paid and hence would demand a better wage compared to the relatively less aware home-based

${ }^{11}$ Only 17 per cent of the respondents in the large-scale industry had an appointment letter or any other document of employment. The only sector where legal requirements of employment were followed to a significant extent was the pharmaceutical sector where about 35 per cent of the women workers interviewed had received a letter of employment. 
worker. Secondly, working hours and days in home-based work were slightly more irregular than in factory work. ${ }^{12}$

Table 3. Incomes Within the Informal Sector (in Rs. per Month)

\begin{tabular}{ll}
\hline Industry & Income \\
\hline Small Scale & 1950 \\
Home based & 1500 \\
\hline
\end{tabular}

Comparison with the minimum wage criterion within the informal sector reveals that there is a significant difference between those working in small factories and home-based workers. In small-scale enterprises, we observed that 61 per cent of women earn below the minimum wage as compared to more than three fourths of home based workers.

\section{Chart 5: Income Above and Below Minimum Wage within the Informal Sector}

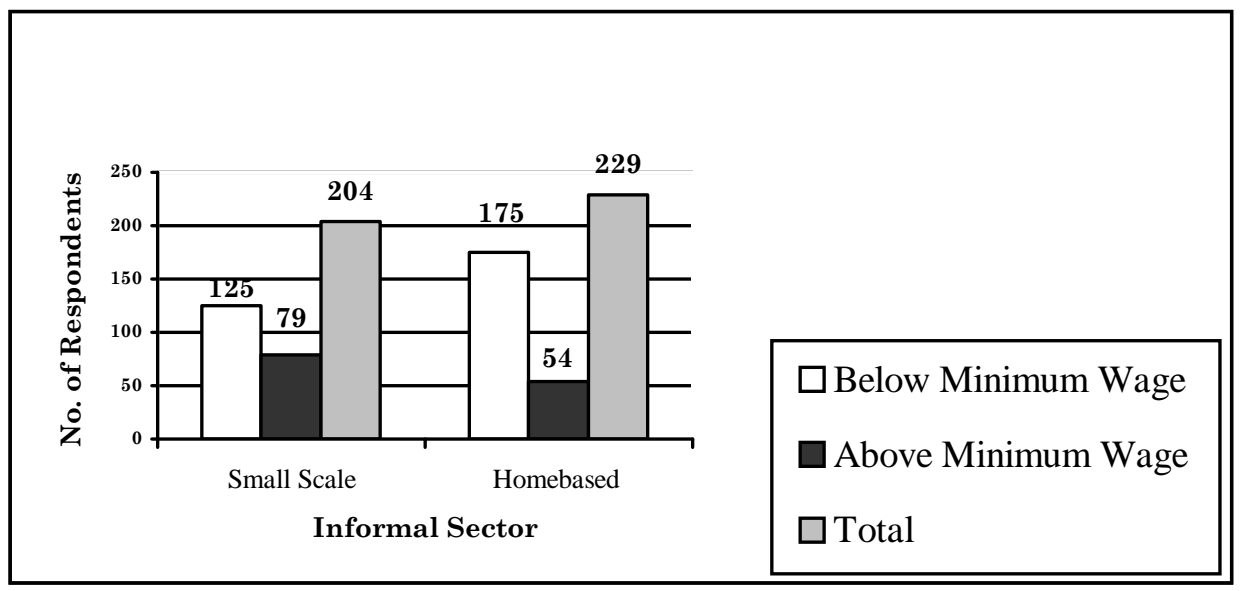

\subsection{Wage Differentials Across Industries}

The industry one works in is also an important determinant of wages. Wages across different industries is given in Table 4. We see that remuneration

\footnotetext{
12 Mean working hours in a day in small enterprises was 8 hours with a standard deviation of 2, whereas in home-based work the mean working hours were 7 with a standard deviation of 3. Mean working days in the week in both categories was the same (6 days) with 0 standard deviation in small scale and 1 in home-based work. For further details see Sayeed and Khattak (2001).
} 
in pharmaceuticals and garments is a good 30 per cent higher than those in plastics and the food sector. Higher wages in pharmaceuticals is due to two factors. First, pharmaceutical manufacturing is more capital and skill intensive than the other sectors. Second, in our sample, the number of questionnaires from LSM in pharmaceuticals was higher than those in other sectors. ${ }^{13}$ Though this introduces a sampling bias, the nature of the industry in itself is an important reason for higher wages paid in the industry.

Table 4. Income Pattern Across Different Industries (in Rs. per Month)

\begin{tabular}{ll}
\hline Sector & Income \\
\hline Plastic & 1800 \\
Pharmaceutical & 2000 \\
Garment & 2000 \\
Food & 1500 \\
\hline
\end{tabular}

Garments, however, paint a slightly different picture. Higher productivity in the sector, determined partly by its internationally competitive nature and partly by the relatively higher skill intensity of work would explain the relatively better wage structure in the industry rather than across the formal-informal divide. Indeed if we look at detailed data across the formal and informal sectors within garments in all the cities the wage differential is the narrowest in this industry.

The food and plastics sectors are relatively unskilled and mostly cater to the local or national market. The food sector is particularly interesting. Although the share of LSM in the food sector is more than in plastics and garments, the median wage in the sector is lowest in our sample. The nature of the industry - where the capital-labour ratio is the lowest appears to explain lower wages.

Wage differentials across sectors, though not significant, do bring out the differences in the nature and structure of industry as determinants of wage differentials in the sample. It appears that skill and technology intensive industries where the quality of product is important provide better wages than industries, which have less skill intensity. Industry structure, as we saw above, matters but much more important a determinant of wage differentials is the industry one is employed in.

${ }^{13}$ In Pharmaceuticals, 48.4 per cent of the questionnaires were from LSM, whereas in plastics, garments and food the relative proportion of LSM was 24.2 per cent, 21.4 per cent and 32.2 per cent respectively. 
If we divide the sample on the basis of minimum wages, a similar pattern emerges. Roughly 75 per cent of the workers in plastics and food work below the minimum wage whereas the proportion in Pharmaceuticals and Garments is slightly more than 50 per cent.

\subsection{Regional Variation in Incomes}

The other important determinant of women's incomes will be different dynamics of the labour market in different regions. Differences in the labour force participation rates of women, in the degree of segmentation of the labour market in different cities and the differences in the real wage (given variable cost of living in different cities) can be an important determining factor of wages.

The median wage structure across cities is given in Table 5. We see that in the LSM, Quetta has the highest wage, followed by Karachi, Lahore and Peshawar respectively. Quetta is, however, an out-lier because of the small sample size there (of only 7 and that also clustered in only the pharmaceutical industry). For the other three cities we see that there is tremendous variation in the median wage in LSM, with Lahore one third less than Karachi and Peshawar almost one half of Lahore. Since the sample across the three cities is fairly evenly divided across sectors, ${ }^{14}$ regional differences seem significant in this case. This is attributable to different labour force participation rates in cities, education and skill levels of women as well as the level of industrialisation in different regions.

In the small-scale sector, however, the data throws up some surprises. Whereas the wage structure in Karachi and Lahore is the same with Peshawar lagging behind by roughly one-fourth less. ${ }^{15}$ Since the sample is fairly similar across the three cities, we see that the labour market for small-scale industry behaves in a fairly similar fashion in Karachi and Lahore with returns to women's labour being lower in Peshawar. However, once lower commodity prices and hence the higher purchasing power in Peshawar is taken into consideration, the difference in the real wage narrows down also. Since the small-scale sector is one area where the labour market operates in an unregulatory capacity, this sector provides the best indicator of labour market dynamics across cities. Our results thus reveal that once real wage differentials are taken into account there appears to be very little difference in labour market dynamics across regions for female employment.

\footnotetext{
${ }^{14}$ The only exception being that there are no responses in garments in Peshawar.

${ }^{15}$ Quetta has a negligible sample of only one respondent in small industry.
} 
Table 5. Median Wage in Different Cities Across Industry Type

\begin{tabular}{lllll}
\hline Industry & Karachi & Lahore & Peshawar & Quetta \\
\hline Large Scale & 3000 & 2000 & 1050 & 5000 \\
Small Scale & 2000 & 2000 & 1500 & 800 \\
Home based & 850 & 2000 & 2000 & 1250 \\
\hline
\end{tabular}

In the home-based sector we see that the median wage in Karachi is much lower than the other cities and Lahore and Peshawar have similar wages in this form of women's work.

The lower wage in Karachi may be due to the fact that a larger proportion of the sample in the other three cities consists of garment workers whereas the sample in Karachi is fairly spread out across the four industry sectors. ${ }^{16}$ Earning differentials in this industry type therefore appear to be explained by the sector in which women are working.

\section{Human Capital and Experience as Determinants of Returns to Labour}

Earnings are also expected to be determined by attributes of human capital. To check whether human capital accumulation by women workers results in change in earnings, we have regressed earnings of workers on the years of schooling received and experience they attain while working in the industry. The framework applied is similar to the one developed by Becker (1964) and Mincer (1974) and is considered the standard approach to estimate returns to human capital. Previously in the context of Pakistan, Khan and Burki (1993) have used this approach to challenge the dual labour market hypothesis, which downplays investments in human capital in the informal sector.

The statistical earnings function takes the form.

$\ln y_{i}=f\left(s_{i}, x_{i}, z_{i}\right)+u_{i}, \quad i=1, \ldots n$

where

In $y_{i}=$ natural log of earnings or wages for the ith individual

$s_{i}=$ measure of schooling

$x_{i}=$ indexes experience

${ }^{16}$ We also checked for the number of hours worked by home based workers to see if that explains the difference in earning profiles across cities. But working hours and days are constant across cities and sectors. 
$z_{i}=$ other factors affecting wages

$u_{i}=$ random disturbance term

The regression equation has the following specification:

$$
Y=\alpha+\beta_{1} X_{1}+\beta_{2} X_{2}+\beta_{3} X_{2}^{2}+\mu .
$$

Where

$$
\begin{aligned}
& Y=\text { Log of hourly income of women } \\
& X_{1}=\text { Years of schooling } \\
& X_{2}=\text { Experience } \\
& X_{2}^{2}=\text { Square of experience variable } \\
& \mu . \quad=\text { Error Term }
\end{aligned}
$$

\subsection{Education and Experience Profile of Respondents}

Before presenting the result, it is important to provide some information on the educational and experiential attributes of the sample. In the sample as a whole, two-thirds of the respondents were literate with a minimum qualification of primary education. As expected, the highest proportion of literate women was in large-scale manufacturing (approximately 84 percent) followed by small-scale and home based work with distributions of 65 and 54 percent respectively. Although, the literacy profile corresponds with the type of industry in which these women were working, the unusual result which emerges is the significant number of literate women in home-based work. This is a surprising result against the general expectation that home-based work is usually associated with either illiterate women or those who have very little or no education. Regionally, the highest number of literate women belonged to Peshawar i.e. 77 per cent, followed by Karachi ( 72.3 per cent), Lahore (62 per cent) and Quetta (46.7 per cent). The reason for higher literacy levels in Peshawar is explained by the fact that 90 per cent of the women interviewed in home-based work were found to be literate. Detailed statistics of the education profile is presented in Table 6 given below. 
Table 6: Percentage Distribution of Education Level by Industry Type and City

\begin{tabular}{|c|c|c|c|c|c|}
\hline & Karachi & Lahore & Peshawar & Quetta & Total \\
\hline \multicolumn{6}{|l|}{ Large scale } \\
\hline Primary and Above & 23.8 & 36.3 & 55.9 & 71.5 & 37.4 \\
\hline $\begin{array}{l}\text { Secondary and } \\
\text { Above }\end{array}$ & 76.2 & 63.7 & 44.1 & 28.5 & 62.7 \\
\hline \multicolumn{6}{|l|}{ Small scale } \\
\hline Primary and Above & 39.6 & 53.3 & 47.8 & 0 & 47.0 \\
\hline $\begin{array}{l}\text { Secondary and } \\
\text { Above }\end{array}$ & 60.4 & 76.6 & 52.1 & 0 & 53.0 \\
\hline \multicolumn{6}{|l|}{ Home-based } \\
\hline Primary and Above & 70.3 & 67.5 & 30.7 & 54.5 & 58.4 \\
\hline $\begin{array}{l}\text { Secondary and } \\
\text { Above }\end{array}$ & 29.7 & 32.5 & 69.2 & 45.4 & 41.6 \\
\hline
\end{tabular}

Overall, the average work experience of the respondents comes to approximately 6 years. Industry wise, women performing home-based work have the highest average experience of 8 years whereas women in small scale and large-scale manufacturing have five years of experience on average.

\subsection{Regression Results}

The regression was run separately for the overall sample, formal sector and informal sector including small scale and home-based work (see Table 7). The results show that for the total sample, the coefficients for schooling, experience, and experience square, have been found to be significant. The average rate of return of one additional year of schooling is 8 percent whereas an additional year of experience results in 3 per cent increase in wage. The negative coefficient of experience square shows that the returns to experience decline at the margin. More specifically, the earnings growth is 2.8 per cent at one year, 2 per cent at 5 years of experience, 1 per cent at 10 years until it reaches zero at 15 years of experience.

The estimated coefficients of formal sector workers have been found to be significant meaning that schooling and experience have positive returns, whereas earnings decline after a specific period of experience. After one, five and ten years of experience, the earnings growth decline by 12, 8, and 3 per cent until it reaches zero at 13 years of experience. Importantly, the result shows that earnings of formal sector workers declines earlier compared to the 
aggregate sample. This is explained by the fact that in large-scale or formal sector manufacturing, the labour force tends to be semi-skilled and relatively younger unmarried women; they are easily replaced when they marry by other younger cohorts (Standing 1989). Because of this early retrenchment of workers, their age-earnings curve falls earlier.

In the informal sector, experience and experience-square have been found to be insignificant which implies that accumulation of more experience does not result in growth of wages. Since the women which comprised the sample of the informal sector were performing highly labour intensive, least skilled tasks in almost all the industrial sectors selected, ${ }^{17}$ it appears that attaining more experience in such tasks does not result in improving their returns to labour.

Importantly, the returns to education in the informal sector are marginally more significant than in the formal sector. The reason for marginally higher returns of education in the informal sector is explained by the preference of relatively more educated women by the subcontractor. Since women in the informal sector are less educated than workers in the formal sector, the middlemen or contractors would prefer to contract out work to relatively more educated women as it is easier to convey to them specifications and quality of work that is required.

Table 7: Regression Results for Overall, Formal and Informal Sectors

\begin{tabular}{llll}
\hline & Total & Formal & Informal \\
\hline Constant & 1.53 & 1.58 & 1.58 \\
Schooling & $0.09(7.50)$ & $0.06(4.44)$ & $0.08(5.31)$ \\
Experience $^{2}$ & $0.03(2.23)$ & $0.13(7.98)$ & $0.01(-0.30)$ \\
Experience $^{2}$ & $-0.001(-1.57)$ & $-0.005(-6.85)$ & $0.0004(0.67)$ \\
$\mathrm{R}^{2}$ & 0.13 & 0.38 & 0.11 \\
F-Statistic & 20.54 & 31.98 & 9.80 \\
$\mathrm{~N}$ & 406 & 158 & 248 \\
\hline
\end{tabular}

(t-statistics are in parenthesis)

Note: All coefficients have been found to be significant at the 5 per cent level.

${ }^{17}$ For instance in the plastics sector, women were found to be performing the least skilled tasks such as cleaning and sorting of raw materials whereas in Pharmaceuticals, the respondents were doing packaging of drugs and medicines. Similarly, in the food sector, women were usually working as packers of processed food items such as sweets, toffees, biscuits, and chocolates, etc. Garment sector is the only exception where women were found stitching clothes and other apparel accessories. 


\section{Conclusion}

Results presented in this paper generally confirm many of the hypotheses we started with. On income patterns and their determinants, we see that roughly two thirds of the sample works below the official minimum wage at the time.

Data analysis also shows that by and large earning differentials are explained by industry type, i.e. if a woman happens to be working in a large scale formal sector industry, her earning profile is expected to be better than those in the informal sector. In the informal sector, earning profiles are better for those working in small-scale industry than those doing homebased work. The earning profile of women workers is also determined by the industry a woman is working in. The more capital and skill intensive the industry or one with greater quality control requirements will provide better wages. The only surprising result is that there is no significant differential in the workings of the labour market across different regions.

Overall, human capital -in terms of schooling, and experience - also has a positive relationship with earnings. However, in the informal sector, according to our sample, returns to experience have been found to be insignificant implying that attainment of more experience over the years does not have positive returns in terms of wages. The unskilled nature of tasks which women perform are not remunerated accordingly in the labour market irrespective of the level of experience as indicated by our sample. This illustrates the unregulated nature of the informal economy where labour laws are not applicable. 
154 The Lahore Journal of Economics, Vol.8, No.1

\section{References}

Becker, G. S. 1964. "Human Capital: A Theoretical and Empirical Analysis with Special Reference to Education.” National Bureau of Economic Research, New York.

Burki, Abid. A. and Khan, Mushtaq A. 1993. "Returns to Human Capital in the Informal Sector: Some Evidence." In Sabur Ghayur (ed.) The Informal Sector of Pakistan: Problems and Policies. Friedrich Ebert Stiftung, Islamabad.

Bainbridge, W. S. 1992. "Social Research Methods and Statistics-A Computer Assisted Introduction.” Wadsworth Publishing Company, Belmont, CA.

Government of Pakistan (GOP). Labour Force Survey 1996-97, Federal Bureau of Statistics, Islamabad.

Kazi, S. 1990 "Special Problems of Women's Employment in Pakistan.” Planning Division, GOP, 1990.

Kazi, S. and Sathar 1993. "Informalisation of Women Workers: Consequences for Fertility and Child Schooling in Urban Pakistan.” Pakistan Development Review (32) Part 2, Winter.

Kazi, S 1999. "Gender Inequalities and Development in Pakistan.” in Khan S.R. (ed.) Fifty Years of Pakistan's Economy, Oxford University Press, Karachi.

Mammen, K and Paxson, C. 2000. "Women's Work and Economic Development." in Journal of Economic Perspectives, 14(4).

Mincer, J. 1974. "Schooling, Experience and Earnings.” National Bureau of Economic Research, New York.

Sayeed, A. 2002. "The Need and Feasibility of a Minimum Wage in Pakistan.” NIPA Journal, Vo1 7, No. 2.

Sayeed, A. and Khattak, S. 2001. "Women's Work and Empowerment Issues in an Era of Economic Liberalisation: A Case Study of Pakistan's Urban Manufacturing Sector.” Pakistan Institute of Labour Education and Research, Karachi.

Standing, G. 1989. “Global Feminisation Through Flexible Labour.” World Development, Vol. 17, no.7. 